\title{
Changes of eating pattern of Hokkaido native horses in winter
}

\author{
Y Asahida, S Kondo, M Kawai, T Yasue, K Ogawa, M Okubo \\ Faculty of Agriculture, Hokkaido University, Sapporo, 060 Japan
}

\begin{abstract}
Hokkaido native horses has been kept in the northernmost and snowy-cold region of Japan since previous century. Traditional feeding system of them in winter is grazing bamboo grass (Sasa nipponica) which is a dominant species of plants in the forest in Hokkaido island.
\end{abstract}

In the Livestock Farm of Hokkaido University, a herd of Hokkaido native horses have been kept outdoors all the year round, fed bamboo grass in a woodland pasture from fall through winter. This study is to determine the eating time and pattern of Hokkaido native horses fed bamboo grass in winter forest.

Experimental horses were about 40 mares including 18 to 22 pregnant animals. They were rotationally grazed for 12 paddocks of woodland pasture (about 20 ha each) as a weekly intervals from October to December. Two 24-h behavioural observations was done at 25.4 and 23.2 ha paddocks in November and December at the second day of each grazing period. As a focal animal, a pregnant mare ( $10 \mathrm{yr}$ old, $370 \mathrm{~kg}$ of $\mathrm{BW}$ ) in the herd was purchased continuously through each $24 \mathrm{~h}$, and each time-budget of eating were recorded. Another 24-h behavioural observations were done on 4 colts of the same breed (mean BW:
$253 \mathrm{~kg}$ ), kept in each individual stable and fed grass hay as a maintenance level.

Ambient temperatures through observations in woodland pasture was from -3.3 to 6.5 degree of $C$, while in stables it ranged 11.1 to 17.2 degree of $\mathrm{C}$. The mean eating time of stable horses was 491 minutes/day. There was no body weight gain of them. In winter forest, and grazing bamboo grass, horses showed 880 to 960 minutes of eating, and the body weight had little change during the period. Mayes and Duncan (1986, Behaviour, 96, 962-965) described that a general eating pattern of horses in grazing had 2 peaks, dawn and dusk. In this study, colts in stables showed their main eating in 18-24 $\mathrm{h}(40.6 \%)$ and $06-12 \mathrm{~h}$ $(37.4 \%)$, and little eating in 24-06 h $(0.8 \%)$. The horse grazing in forest did not show such a clear 2 peak pattern, but showed night grazing (24-06 h) besides dawn and dusk eating. Other native horses on pasture in southern area of Japan (Kaseda, 1983, Jpn J Zootech Sci, 54, 464-469) showed less eating and more resting in 24-06 $\mathrm{h}$ than this study. These additional eating of bamboo grass in 24$06 \mathrm{~h}$ may be a behavioural response to cold ambient temperature in this time-period for winter forest grazing.

\begin{tabular}{lccccc} 
Experimental & $\begin{array}{c}\text { Minutes } \\
\text { of } \\
\text { eating }\end{array}$ & $12-18 \mathrm{~h}$ & $18-24 \mathrm{~h}$ & $24-06 \mathrm{~h}$ & $06-12 \mathrm{~h}$ \\
site (area) & & 26.6 & 30.5 & 16.4 & 26.5 \\
& & & \multicolumn{4}{c}{$\begin{array}{c}\text { Occurrence of eating (\%) } \\
\text { between each quarter of day }\end{array}$} \\
Forest (25.4 ha) & 880 & 27.1 & 26.9 & 19.6 & 26.4 \\
Forest (23.2 ha) & 960 & & & &
\end{tabular}

